\title{
EDITORIAL
}

\section{Does nature know best?}

Whenever nutritionists discuss nutrient requirements for different stages of the life cycle or for different physiological conditions, a question that often arises is 'does nature know best?' and it is one that is usually extremely difficult to answer.

Two examples can illustrate different aspects of this question. During a normal pregnancy, the fetus accumulates on average $30 \mathrm{~g}$ of calcium which must come from the mother's circulation. It may be natural to assume that there is an extra dietary requirement for this element during pregnancy yet there is little evidence for a natural increase in food intake during a normal pregnancy, certainly not enough to provide this amount of $\mathrm{Ca}$. Should we then give supplements, since nature has been thoughtless enough not to provide for women spontaneously to increase their intake? Or could it be that her body reserves (bone) were meant for this purpose and can be replenished later when these extra demands are over? Does nature know best?

The second example concerns iron, which is required in quantities some fifty times lower than $\mathrm{Ca}$. It is well-known that milk is a poor source of $\mathrm{Fe}$ and were it not for reserves built up by the fetus, the infant would surely be deficient in this nutrient before weaning. Fetal reserves must come from the mother whose own diet may frequently contain relatively small amounts of $\mathrm{Fe}$ and foods from which $\mathrm{Fe}$ has low bioavailability. If we think that either the mother, the baby or both may lack sufficient Fe for metabolism to function at its optimum, should we supplement the diet of either or will nature, by processes of adaptation in the absorption or utilization of $\mathrm{Fe}$ or by paying from reserves to be replenished later, ensure that in the long term, requirements will be satisfied without the intervention of the nutritionist? If we do decide to supplement, what other consequences will there be? Do we yet know enough to be confident that what is done with all good intentions is not going to alter the metabolism of other nutrients so that, overall, we may have done more harm than good? As discussed in an earlier editorial, it is fatally easy to think only in terms of the nutrient of current interest, when it is the intricate network of interactions between nutrients that must be considered.

These are considerations probed by Southon et al. (1989) in this issue. These authors were concerned about the lack of understanding of how the common practice of Fe, folate and $\mathrm{Ca}$ supplementation may influence zinc nutrition. Due to the inherent problems of studying these interactions quantitatively in human subjects, they chose pregnant and nonpregnant rats as their experimental model and compared $\mathrm{Zn}$ absorption and $\mathrm{Zn}$ status with those of animals fed on unsupplemented diets. The additional amounts of $\mathrm{Fe}, \mathrm{Ca}$ and folic acid in the supplemented diets were calculated to be similar to the proportional increase in intakes of women who increased their daily $\mathrm{Ca}$ intakes from 500 to $1200 \mathrm{mg}$ (the respective 1979 UK recommended daily amounts (RDAs); Department of Health and Social Security, 1979) and who routinely take a commonly prescribed Fe-folate supplement throughout pregnancy. Because the level of dietary $\mathrm{Zn}$ may also be important, they compared the effect of supplementation on ${ }^{65} \mathrm{Zn}$ absorption in rats given diets containing two-thirds or five times the dietary concentration of $12 \mathrm{mg} \mathrm{Zn} / \mathrm{kg}$ recommended by the American Institute of Nutrition (1977).

Supplementation always resulted in significant reduction of ${ }^{65} \mathrm{Zn}$ retention and lower 
plasma $\mathrm{Zn}$ concentrations of the supplemented animals but did not result in any reduction of $\mathrm{Zn}$ concentration of the fetuses. Pregnancy resulted in an increased ability to retain $\mathrm{Zn}$ only if the diet contained a low concentration of $\mathrm{Zn}$. The $\mathrm{Ca}$ content of the femur was lower in the animals given the higher levels of $\mathrm{Zn}$, and the Fe content of the fetuses was lower when the mothers had received high levels of $\mathrm{Zn}$.

This paper graphically illustrates the complexities of nutrient interactions and hints at possible pitfalls of unthoughtful supplementation. It also illustrates the need for caution in the interpretation of the concept of 'nutritional status'. The statistically significant reduction in plasma $\mathrm{Zn}$ concentration, which might be taken as an indication of 'status', had no practical effect on the pregnancy or on the $\mathrm{Zn}$ content of the fetuses. Several different indices of nutrient status may be needed to obtain a composite picture to be used in the final judgement as to whether any particular nutrient intervention is effective or harmful. We can legitimately ask how well the pregnant rat performs as a model for the pregnant woman. We know, for example, that the sow behaves somewhat differently in response to adaptation in the efficiency of $\mathrm{Zn}$ absorption during pregnancy (Kirchgessner et al. 1982) and we may suspect that known differences between species in placental structure and permeability to nutrients may limit our ability to make precise extrapolations. The authors concede that their model represents a somewhat extreme situation in the length of time over which supplementation was applied and the range of $\mathrm{Zn}$ concentrations studied. Nevertheless we have always to consider those people on the edges of the distributions of requirements or intakes. We don't know who they are but we infer they must exist and, in view of the essential role of $\mathrm{Zn}$ in metabolism and the uncertainties about the long term and perhaps silent consequences of marginal $\mathrm{Zn}$ depletion, it may be wiser to adopt a cautious approach to excessive $\mathrm{Fe}$, folate and $\mathrm{Ca}$ supplementation during pregnancy unless there are clear indications that it is necessary. Such strictures are timely in view of the widespread interest in nutritional supplements, often unsupervised and not subject to any medical or dietetic advice.

Another paper in this issue, that of Schofield et al. (1989), deals with what British women are actually eating in terms of $\mathrm{Ca}$, retinol, ascorbic acid and folic acid. Their methodology has been described in an earlier volume of this Journal (Schofield et al. 1987). It is common for editors of journals, when assessing papers concerned with food/nutrient intakes, to be critical of the methodologies employed. It is worth commenting that no method is ideal and that those favoured as being the most 'rigorous' may not necessarily be the most appropriate. The authors point out that some subjects refused to do a 3-d weighed inventory and remind us that early pregnancy and the period immediately after childbirth is a stressful time for most women. It is better, therefore, to have the cooperation of a greater number of willing subjects in providing data by a less rigorous method (in this case, food diary) which is also likely to avoid the problems that the more stressful methods may encourage, e.g. a change in normal eating habits.

This paper compared intakes in women from the whole spectrum of social classes twice during pregnancy and once post-partum, in London and Edinburgh. For retinol, $\mathrm{Fe}$, ascorbic acid and folic acid there were consistent regional and social class gradients in intakes, favouring London women in 'non-manual' social groups and leaving Edinburgh 'manual class' women after pregnancy with the lowest intakes. Such consistencies were difficult to discern for $\mathrm{Ca}$ but, in Edinburgh at least, the intakes were significantly higher in lactating women. Ca was the only nutrient for which some mean intakes were higher in Edinburgh than those of comparable groups in London.

The authors discuss the implications of the fact that $\mathrm{Ca}$ and Fe intakes were consistently below the current UK RDAs (Department of Health and Social Security, 1979), while retinol intakes were all above it and ascorbate intakes ranged above and below the RDA. 
In view of the definition of the 1979 RDA, we should not be surprised at intakes below the RDA and should only be concerned when significant numbers of people are receiving intakes considerably below the RDA. This, of course, presumes that the RDAs are realistic estimates of requirements for most people in the appropriate groups. At a time when UK RDAs are being systematically overhauled (Whitehead, 1989), this is a question of considerable importance and the Chairman of the Editorial Board invites helpful and informed discussion in the correspondence column of this Journal.

Michael I. GuRr

\section{REFERENCES}

American Institute of Nutrition (1977). Report of the American Institute of Nutrition ad hoc committee on standards for nutritional studies. Journal of Nutrition 107, 1340-1348.

Department of Health and Social Security (1979). Recommended daily amounts of food energy and nutrients for groups of people in the United Kingdom. Report on Health and Social Subjects no. 15. London: H. M. Stationery Office.

Kirchgessner, M., Schwarz, F. J. \& Roth-Maier, D. A. (1982). Changes in metabolism of copper, zinc and manganese in gravidity and lactation. In Trace Element Metabolism in Man and Animals, pp. $85-88$ [J. M. Gawthorne, J. M. C. Howell and C. C. White, editors]. Berlin : Springer-Verlag.

Schofield, C., Stewart, J. \& Wheeler, E. (1989). The diets of pregnant and post-pregnant women in different social groups in London and Edinburgh: calcium; iron, retinol, ascorbic acid and folic acid. British Journal of Nutrition 62, 363-377.

Schofield, E. C., Wheeler, E. \& Stewart, J. (1987). The diets of pregnant and post-pregnant women in different social groups in London and Edinburgh: energy, protein, fat and fibre. British Journal of Nutrition 58, 369-381.

Southon, S., Wright, A. J. A. \& Fairweather-Tait, S. (1989). The effect of combined dietary iron, calcium and folic acid supplementation on apparent ${ }^{65} \mathrm{Zn}$ absorption and zinc status in pregnant rats. British Journal of Nutrition 62, $415-423$.

Whitehead, R. G. (1989) Editorial. British Journal of Nutrition 61, 123-124. 